\title{
Effects of Vitamin D and Simvastatin on Inflammatory and Oxidative Stress Markers of High-Fat Diet-Induced Obese Rats
}

\author{
Abdel-Moniem A. Makhlouf ${ }^{1}$, Atef M. Mahmoud ${ }^{2}$, Rania G. Ibrahim ${ }^{1}$, Yasmeen S. Abdel Aziz \\ ${ }^{I}$ Faculty of Science, Fayoum University, Egypt \\ ${ }^{2}$ Research institute of ophthalmology, Egypt \\ ${ }^{3}$ Water Pollution lab, Fresh Water Division, National Institute of Oceanography and Fisheries, Egypt
}

\begin{tabular}{|c|c|}
\hline Article Info & Abstract \\
\hline Article history: & Purpose: This study was aimed to evaluate the antioxidant and anti- \\
\hline Received:10 May 2021 & $\begin{array}{l}\text { inflammatory effects of vitamin D and Simvastatin (SIM) on a high-fat diet } \\
(H F D) \text { induced-obese rats. }\end{array}$ \\
\hline $\begin{array}{l}09 \text { August } 2021 \\
\text { d:11 August } 2021\end{array}$ & Methods: 40 adult male rats were divided into four groups: control group, \\
\hline & $\begin{array}{l}H F D, H F D+\text { vitamin } D \text {, and HFD }+ \text { SIM for } 14 \text { weeks. Vitamin } D \text { or SIM } \\
\text { supplementation was done for the last } 6 \text { weeks. Vitamin D dosage was } 500\end{array}$ \\
\hline Keywords: & IU/kg, while SIM dosage was $10 \mathrm{mg} / \mathrm{kg}$. Interleukin-6 (IL-6) concentration \\
\hline $\begin{array}{l}\text { Simvastatin, Vitamin D, HFD, } \\
\text { Oxidative stress, Inflammation }\end{array}$ & $\begin{array}{l}\text { and markers of oxidative stress including malondialdehyde }(M D A) \text {, } \\
\text { superoxide dismutase }(S O D) \text {, glutathione peroxidase }(G P x) \text {, and reduced }\end{array}$ \\
\hline Paper & glutathione $(G S H)$ concentrations in serum were determined using ELISA \\
\hline Research Article & kits and spectrophotometry methods, respectively. \\
\hline Correspondence $A$ & and MDA and increases SOD, GPx activities, and GSH levels. Oxidative \\
\hline Abdel-Moniem A. & stress can result not only from increased ROS production but also from \\
\hline Makhlouf & dysfunctional antioxidant defenses. \\
\hline Email: rg1118@fayoum.edu.eg & $\begin{array}{l}\text { Conclusion: From the experimental results, it was observed that SIM and } \\
\text { vitamin D could attenuate oxidative stress and inflammation markers } \\
\text { associated with obesity. }\end{array}$ \\
\hline
\end{tabular}

\section{Introduction}

Obesity is a serious problem posing a considerable threat to human health (Ni et al., 2020). Obesity is a multifactorial disease caused by chronic positive energy surplus or secondary to genetic, hypothalamic, and endocrine diseases (Vallgårda et al., 2017). Obesity is characterized by excessive fat deposition into adipose tissue and non-adipose tissues (Kelishadi et al., 2017). Another characteristic feature coupled with obesity is the alteration of the redox state accompanied by metabolic risk factors (Warolin et al., 2014). Obesity and its related metabolic disorders are also strongly linked to oxidative stress. This oxidative status is closely associated with proinflammatory cytokine secretion, which can initiate oxidative stress in a continuous circle (Biswas, 2016). As a result, systemic oxidative stress and inflammation are critical factors in the pathogenesis of obesity-related diseases (Crujeiras et al., 2013). 
Several strategies have been developed to modulate oxidative stress and inflammation associated with obesity, which aims to decrease disease risk factors, including weight loss, physical activity, and dietary intervention (Bigornia et al., 2010). Previous studies have recommended that at least a $10 \%$ reduction of the total body weight could alleviate proinflammatory and oxidative stress parameters (Ford, 2002; Church et al., 2011). However, this weight reduction strategy may not be suitable for the general population (Bruun et al., 2006; Kelly et al., 2007).

Other studies have examined dietary intervention efficacy, including changes in macronutrient intakes and caloric restrictions in the management of oxidative stress and inflammation (Huang et al., 2015). However, one of the most effective dietary interventions is vitamin D. Vitamin D, a non-enzymatic antioxidant, has been defined as a potent preventive and therapeutic agent for the obese (Moukayed \& Grant2019). Moreover, vitamin D is well known for its potential role in managing obesity-induced oxidative stress Reid \& Li, (2001).due to its significant role in decreasing lipid hydroperoxide Garcion et al. (1999) and increasing total antioxidant status (TAS) and oxidative capacity in monocytes (Wu et al., 2011), as well as its antiinflammatory effect (Gode et al., 2016).

Another strategy to attenuate inflammation and oxidative stress depend on using lipidlowering agents such as statins (Sahid et al., 2017; Rodrigues et al., 2019). Simvastatin, a member of the statin group, inhibits rate-limiting enzymes in cholesterol biosynthesis. Recently, Simvastatin has attracted more attention due to its non-lipid properties. Hence, it could modulate inflammatory and oxidative stress cascades induced during obesity through its pleiotropic effects besides its lipid-lowering properties (Csonka et al., 2016).

This study aimed to evaluate the effect of HFD on inflammation and oxidative stress induction in serum of adult male Wistar rats. Moreover, to examine the impact of vitamin D and Simvastatin administration in ameliorating oxidative stress and inflammation in these animals.

\section{Methodology and Procedures}

\section{Animals}

Forty adult male Wistar rats (8 weeks of age), weighing about 145-165 g, supplied by the Animal House of the Research Institute of Ophthalmology, Giza, Egypt. The animals were individually housed in stainless-steel cages under conventional controlled conditions (12-h light/dark cycle with a temperature of $24 \pm 1{ }^{\circ} \mathrm{C}$ and relative humidity of $50 \pm 10 \%$ ), fed with a standard laboratory pellet diet, and had free access to distilled water ad libitum. At the end of the first week, the animals were randomly divided into four groups: (1) control group (Control $\mathrm{n}=10$, fed with standard diet), (2) HFD group ( HFD n=10 was fed with HFD), (3) vitamin D group (vitamin D $\mathrm{n}=10$, fed with HFD and supplemented with vitamin D 500IU/kg/day at the last 6 weeks), (4) SIM group (SIM n=10 fed with HFD and treated with SIM $10 \mathrm{mg} / \mathrm{kg} / \mathrm{day}$ ). All four groups were given their respective treatments for 14 weeks (Fig.1). In addition, vitamin D and SIM were supplemented for the last 6 weeks by oral gavage. All experimental animal protocols 
were carried out according to the standards of the Guide for the Care and Use of Laboratory Animals and approved according to the Animal Experimentation Ethics Committee of Animal Research of the Research Institute of Ophthalmology, Giza, Egypt. The composition of the experimental diet (G/Kg diet) was according to the formula (Sobesky et al., 2014)

\begin{tabular}{|c|c|c|c|}
\hline $\begin{array}{l}0-1 \text { weeks } \\
\text { Habituate }\end{array}$ & $\begin{array}{c}\text { 2-9 weeks } \\
\text { Feed by } \\
\text { ND/ HFD }\end{array}$ & $\begin{array}{c}10-15 \text { weeks } \\
\text { Feed by ND/ } \\
\text { HFD\& } \\
\text { vitamin D/ } \\
\text { HFD \& } \\
\text { SMV. }\end{array}$ & $\begin{array}{c}\text { Scarifice \& } \\
\text { Lab tests \& } \\
\text { histology } \\
\text { examine. }\end{array}$ \\
\hline
\end{tabular}

Figure 1: Overview of the design of the experiment

\section{Diets and drugs}

Standard diet and HFD were purchased from El-Gomhorya Company, Cairo, Egypt. HFD was preserved at $4^{\circ} \mathrm{C}$ until used. SIM (Zocor $10 \mathrm{mg}$ ) was purchased from Merck sharp \& Dohme Ltd., UK. Vitamin D (Calcitriol 500 IU) was purchased from Sigma Aldrich, USA.

\section{Sample collection}

At the end of the experimental period (98 days), the animals were weighed and anesthetized by diethyl ether after overnight fasting. The blood samples were collected through the retro-orbital venous plexus. The blood samples used for serum assessment were collected without using an anticoagulant. First, the blood was allowed to clot for $30 \mathrm{~min}$ at $25^{\circ} \mathrm{C}$. The samples were then centrifuged at $4,000 \mathrm{rpm}$ for $15 \mathrm{~min}$ at $4^{\circ} \mathrm{C}$. After that, the supernatants were stored at $-80^{\circ} \mathrm{C}$ for further assessment, except IL-6 samples were stored at $-20^{\circ} \mathrm{C}$ to avoid loss of bioactive rat IL-6.

\section{Malondialdehyde assessment}

Malondialdehyde levels were measured using the thiobarbituric acid reactive substances (TBARS) method (Ohkawa et al., 1979).

\section{Glutathione peroxidase and superoxide dismutase assessment}

SOD was assayed by a spectrophotometric method based on the inhibition of a superoxideinduced reduced nicotinamide adenine dinucleotide (NADH) oxidation according to Paoletti et al. method Boitard et al., (2014) by using Ransod, Randox kit (UK). GPx activity was measured according to Paglia and Valentine method Erion et al. (2014). using Ransel, Randox kit (UK). 


\section{Reduced glutathione assessment}

GSH was measured using the colorimetric method (Beutler et al., 1963) of Beutler et al. using BioAssay Systems ( USA) kit.

\section{Assessment of interleukin-6}

IL-6 activity was measured according to the ELISA method of Engvall and Perlmann (Engvall \& Perlmann, 1971). using a ThermoFisher kit (USA).

\section{Statistical analysis}

All statistical analyses were performed using SPSS software, version 20. Data were analyzed using one-way analysis of variance (ANOVA) followed by Post hoc-least significant difference (LSD). Data were expressed as the mean \pm SD. $\mathrm{P}<0.05$ was considered statistically significant. All charts were performed using OriginPro for data analysis and graphing software (version 2018).

\section{Results and Discussion}

\section{Change of MDA levels in the studied groups}

According to our results (Fig.2), MDA levels were significantly increased in the HFD group. However, both vitamin D and SIM groups showed a marked depletion compared to the HFD group. Moreover, a significant decrease was detected in the SIM group compared to the vitamin D group.

\section{Change of SOD and GPx activities in the studied groups}

A notable decrease in SOD activities in the HFD group compared to the control group. Conversely, a significant rise was detected in vitamin D and SIM groups versus the HFD group; also, an increase was detected in the SIM group compared to the HFD group and (Fig.2). The current study revealed a significant upwards in GPx in the HFD group compared to the control group. In contrast, a marked decline was detected in the vitamin D and SIM groups compared to the HFD group. However, a non-significant decrease was detected between the two groups (Fig.2).

\section{Change of GSH levels in the studied groups}

Results from the current study showed a significant decrease in the HFD group compared to the control group in serum GSH levels. A further marked decline in GSH levels was detected in both vitamin D and SIM groups compared to the HFD group. However, there was a significant rise in the SIM group compared to the vitamin D group (Fig.2).

\section{Change of IL-6 levels in the studied groups}


A significant rise was detected in IL-6 levels in the HFD group compared to the control group. A remarkable drop was detected in both vitamin D and SIM groups compared to the HFD group. However, the SIM group showed a significant decrease compared to the vitamin D group (Fig.2).
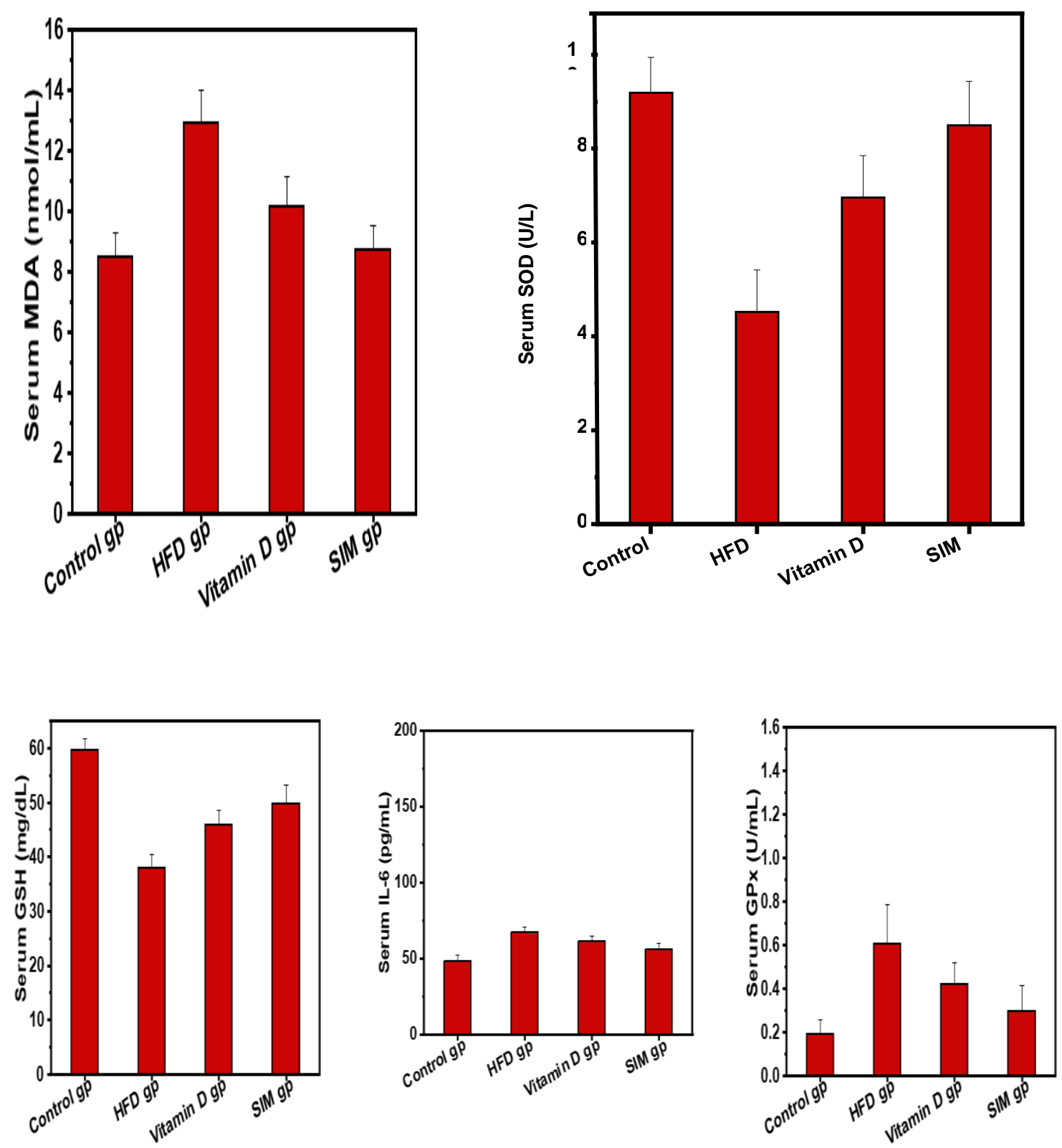

Figure 2: Effect of vitamin D and SIM on parameters of oxidative stress and IL-6 in obese male Wistar rats. 
Obesity is a real pathology as it represents a risk factor for various metabolic diseases (De Lorenzo et al., 2019). Regardless of whether obesity is a condition or a disease, it arises from multiple etiologic determinants, either acquired or inherited (d'Autume et al., 2012). These determinants favor positive energy balance and weight gain (Hall et al., 2009; Popkin \& Hawkes, 2016). Feeding (HFD) to rats was proved to be a valuable model of the putative effects of dietary fat in humans(López et al., 2003). Therefore, rat models are valuable tools for inducing obesity as they will readily gain weight when fed high-fat diets (Von Diemen et al., 2006).

Oxidative stress is an imbalance between tissue free radicals, reactive oxygen species (ROS), and antioxidants (Fernández-Sánchez et al., 2011). Lipid peroxidation is the first step of cellular membrane damage (Repetto et al., 2012). It constitutes a complex chain reaction of free radicals that leads to degradation of polyunsaturated fatty acids (PUFAs) in the cell membrane (Halliwell \& Gutteridge, (1984) and in turn, profound alternations of the cell membrane structure and function (van Ginkel \& Sevanian, 1994). MDA is one of the end-products of the lipid peroxidation process. Thus, increased MDA level is a crucial indicator of lipid peroxidation and oxidative status (Ayala et al., 2014).

The results of the current study were supported by Mahmoudi et al., which demonstrated that the elevation of serum MDA levels is an indicator of lipid damage due to obesity development (Mahmoudi et al., 2019). Also, reduction of MDA levels after vitamin D supplementation was matched by Mostafa et al., which elucidated vitamin D's significant role in ameliorating lipid peroxidation levels and, in turn, inhibiting HFD-induced oxidative stress in obese males Wistar rats (Mostafa et al., 2016). Furthermore, MDA levels were found to be markedly decreased, reaching almost the control level in the SIM group. These results agreed that Eweda et al. proved that SIM could prevent lipid peroxidation and ameliorate oxidative stress induced by the HFD (Eweda et al., 2018)

Furthermore, oxidative stress can result not only from increased ROS production but also from dysfunctional antioxidant defenses. SOD is the first defense against ROS toxicity (Fang et al., 2013) as it catalyzes superoxide radicals dismutation to the less toxic hydrogen peroxide $\left(\mathrm{H}_{2} \mathrm{O}_{2}\right.$ ) (McCord, 1987). Also, GPx, a selenoenzyme, plays a significant role in $\mathrm{H}_{2} \mathrm{O}_{2}$ and hydroperoxide reduction to non-toxic products (Freeman, \& Crapo, 1982). It also has a predominant role in the redox cycling of the reduced glutathione (GSH) to the oxidized glutathione (GSSG), necessary to maintain cells' thiol content to maintain the cell's redox state (Agrawal et $a l ., 2014)$. Therefore, the decrease in SOD and GPx activities could be ascribed to the exhaustion of these enzymes in fighting free radicals generated during the development of obesity (Das et al., 2013; Noeman et al., 2011).

On the other hand, the antioxidant effect of vitamin $\mathrm{D}$ due to its ability to decrease superoxide anion formation; hence these enzymes will not be exhausted in encountering the radicals after vitamin D supplementation. Thus the concentration of SOD and GPx were upregulated (Polidoro et al., 2013). Furthermore, Liang et al. and Pan et al. proved the enhanced expression of SOD and GPx activities after SIM treatment (Liang et al., 2020; Pan et al., 2016). 
Moreover, the thiol-based antioxidant system contributes a second line of cellular defense against ROS-mediated oxidative damage (Nazima et al., 2014). GSH is one of the significant intracellular non-enzymatic antioxidants and the most abundant component of an endogenous cellular "redox buffer" (Kurutas, 2015). The significant decrease could be owing to increased utilization of GSH by cells either as a scavenger of free radicals (Deng et al., 2019). Vitamin D increases GSH levels through the upstream regulation of glutathione reductase (GR) gene expression, a crucial enzyme involved in the synthesis of GSH (Kanikarla-Marie \& Jain, 2016). Also, This upward trend of GSH levels after SIM administration was confirmed by (Feng et al., 2015).

Reactive oxygen species also activate $\mathrm{NF}-\kappa \mathrm{B}$, a redox-sensitive transcription factor that acts as a master regulator of the inflammatory response (Uciechowski \& Dempke, 2020). It is required to induce many inflammatory genes, including those encoding IL-6 (Wang et al., 2014) which could explain the increased levels of IL-6 during obesity. IL-6 is a member of the proinflammatory cytokine family, which induces various proteins expression responsible for acute inflammation (Uciechowski \& Dempke, 2020). Decrease IL-6 levels in vitamin D groups was matched with Kim et al., which confirmed vitamin D impact in the downregulation of IL-6 secretion (Kim et al., 2020). Also, Nicholls et al. illustrated that statins could suppress the modification of proteins by myeloperoxidase-catalyzed reactive nitrogen species. Thus, these species have been demonstrated to promote multiple inflammatory pathways (Nicholls et al., 2006).

\section{Conclusion and Suggestion}

The previous biochemical investigations confirmed the therapeutic effect of vitamin $\mathrm{D}$ and Simvastatin against the deleterious effect of oxidative stress and inflammation induced by HFD, which could reduce the risk of obesity-related disease.

\section{Acknowledgements}

We thank all of the study participants.

\section{References}

Agrawal, S.; Flora, G.; Bhatnagar, P and Flora, S. J. (2014). Comparative oxidative stress, metallothionein induction and organ toxicity following chronic exposure to arsenic, lead and mercury in rats. Cellular and Molecular Biology. 60(2): 13-21.

Ayala, A.; Muñoz, M. F and Argüelles, S. (2014). Lipid peroxidation: production, metabolism, and signaling mechanisms of malondialdehyde and 4-hydroxy-2-nonenal. Oxidative Medicine and Cellular Longevity. 2014: 360438.

Beutler, E.; Duron, O and Kelly, B. M. (1963). Improved method for determination of blood glutathione. Journal of Laboratory and Clinical Medicine. 61: 882-888.

Bigornia, S.J.; Mott, M.M.; Hess, D.T.; Apovian, C.M.; McDonnell, M.E.; Duess, M.A.; Kluge, M.A.; Fiscale, A.J.; Vita, J.A and Gokce, N. (2010). Long-term successful weight loss 
improves vascular endothelial function in severely obese individuals. Obesity. 18(4): 754759.

Biswas, S. K. (2016). Does the interdependence between oxidative stress and inflammation explain the antioxidant paradox?. Oxidative Medicine and Cellular Longevity. 2016: 1-9.

Boitard, C.; Cavaroc, A.; Sauvant, J.; Aubert, A.; Castanon, N.; Layé, S and Ferreira, G. (2014). Impairment of hippocampal-dependent memory induced by juvenile high-fat diet intake is associated with enhanced hippocampal inflammation in rats. Brain, behavior, and immunity. 40: 9-17.

Bruun, J. M.; Helge, J. W.; Richelsen, B and Stallknecht, B. (2006). Diet and exercise reduce lowgrade inflammation and macrophage infiltration in adipose tissue but not in skeletal muscle in severely obese subjects. American Journal of Physiology-Endocrinology and Metabolism. 290(5): E961-E967.

Church, T. S.; Thomas, D. M.; Tudor-Locke, C.; Katzmarzyk, P. T.; Earnest, C. P.; Rodarte, R. Q.; Martin, C.K.; Blair, S.N and Bouchard, C. (2011). Trends over 5 decades in US occupation-related physical activity and their associations with obesity. PloS One. 6(5): e19657-19670.

Crujeiras, A. B.; Díaz-Lagares, A.; Carreira, M. C.; Amil, M and Casanueva, F. F. (2013). Oxidative stress associated to dysfunctional adipose tissue: a potential link between obesity, type 2 diabetes mellitus and breast cancer. Free Radical Research. 47(4): 243256.

Csonka, C.; Sárközy, M.; Pipicz, M.; Dux, L and Csont, T. (2016). Modulation of hypercholesterolemia-induced oxidative/nitrative stress in the heart. Oxidative Medicine and Cellular Longevity. 2016: 1-23.

Das, N.; Sikder, K.; Bhattacharjee, S.; Majumdar, S. B.; Ghosh, S.; Majumdar, S and Dey, S. (2013). Quercetin alleviates inflammation after shortterm treatment in high-fat-fed mice. Food and Function. 4(6): 889-898.

d'Autume, C.; Musher-Eizenman, D.; Marinier, E.; Viarme, F.; Frelut, M. L and Isnard, P. (2012). Eating behaviors and emotional symptoms in childhood obesity: a cross-sectional exploratory study using self-report questionnaires in 63 children and adolescents. Archives de Pediatrie: Organe Officiel de la Societe Francaise de Pediatrie. 19(8): 803810.

De Lorenzo, A.; Gratteri, S.; Gualtieri, P.; Cammarano, A.; Bertucci, P and Di Renzo, L. (2019). Why primary obesity is a disease?. Journal of Translational Medicine. 17(1): 169-182.

Deng, Y.; Tang, K.; Chen, R.; Nie, H.; Liang, S.; Zhang, J.; Zhang, Y and Yang, Q. (2019). Berberine attenuates hepatic oxidative stress in rats with non-alcoholic fatty liver disease via the Nrf2/ARE signalling pathway. Experimental and Therapeutic Medicine. 17(3): 2091-2098.

Engvall, E and Perlmann, P. (1971). Enzyme-linked immunosorbent assay (ELISA) quantitative assay of immunoglobulin G. Immunochemistry. 8(9): 871-874.

46

Copyright (C) 2020-2021, Journal of Scientific Research in Medical and Biological Sciences (JSRMBS), Under the license CC BY- 4.0 
Erion, J. R.; Wosiski-Kuhn, M.; Dey, A.; Hao, S.; Davis, C. L.; Pollock, N. K and Stranahan, A. M. (2014). Obesity elicits interleukin 1-mediated deficits in hippocampal synaptic plasticity. Journal of Neuroscience. 34(7): 2618-2631.

Eweda, S. M.; Rezk, N. L.; Ahmed, A. M and Rezk, O. A. (2018). Effects of vanadium on oxidative stress and electrolytes balance of dyslipidemic male rats treated with Simvastatin. African Journal of Pharmacy and Pharmacology. 12(7): 87-96.

Fang, Y.; Yang, H.; Liu, B and Zhang, L. (2013). Transcriptional response of lysozyme, metallothionein, and superoxide dismutase to combined exposure to heavy metals and bacteria in Mactra veneriformis. Comparative Biochemistry and Physiology. Toxicology and Pharmacology. 157(1): 54-62.

Feng, R.B.; Fan, C.L.; Liu, Q.; Liu, Z.; Zhang, W.; Li, Y.L.; Tang, W.; Wang, Y.; Li, M.M and Ye, W.C. (2015). Crude triterpenoid saponins from Ilex latifolia (Da Ye Dong Qing) ameliorate lipid accumulation by inhibiting SREBP expression via activation of AMPK in a non-alcoholic fatty liver disease model. Chinese Medicine. 10(1): 1-13.

Fernández-Sánchez, A.; Madrigal-Santillán, E.; Bautista, M.; EsquivelSoto, J.; Morales-González, Á.; Esquivel-Chirino, C.; Durante-Montiel, I.; Sánchez-Rivera, G.; Valadez-Vega, C and Morales-González, J.A. (2011). Inflammation, oxidative stress, and obesity. International Journal of Molecular Sciences. 12(5): 3117-3132.

Ford, E. S. (2002). Does exercise reduce inflammation? Physical activity and C-reactive protein among US adults. Epidemiology. 13(5): 561-568.

Freeman, B. A and Crapo, J. D. (1982). Biology of disease: free radicals and tissue injury. Laboratory Investigation Journal. 47(5): 412-426.

Garcion, E.; Sindji, L.; Leblondel, G.; Brachet, P and Darcy, F. (1999). 1, 25-dihydroxyvitamin D3 regulates the synthesis of $\gamma$-glutamyl transpeptidase and glutathione levels in rat primary astrocytes. Journal of Neurochemistry. 73(2): 859-866.

Gode, S.; Aksu, T.; Demirel, A.; Sunbul, M.; Gul, M.; Bakır, I and Yeniterzi, M. (2016). Effect of vitamin D deficiency on the development of postoperative atrial fibrillation in coronary artery bypass patients. Journal of Cardiovascular and Thoracic Research. 8(4): 140-146.

Hall, K. D.; Guo, J.; Dore, M and Chow, C. C. (2009). The progressive increase of food waste in America and its environmental impact. PloS One. 4(11): e7940-7946.

Halliwell, B and Gutteridge, J. M. (1984). Lipid peroxidation, oxygen radicals, cell damage, and antioxidant therapy. Lancet. 1(8391): 1396-1397.

Huang, C. J.; McAllister, M. J.; Slusher, A. L.; Webb, H. E.; Mock, J. T and Acevedo, E. O. (2015). Obesity-related oxidative stress: the impact of physical activity and diet manipulation. Sports Medicine-open. 1(1): 1-12.

Kanikarla-Marie, P. and Jain, S.K. (2016). 1,25 (OH) 2D3 inhibits oxidative stress and monocyte adhesion by mediating the upregulation of GCLC and GSH in endothelial cells treated with acetoacetate (ketosis). The Journal of Steroid Biochemistry and Molecular Biology. 159: 94-101. 
Kelishadi, R.; Qorbani, M.; Djalalinia, S.; Sheidaei, A.; Rezaei, F.; Arefirad, T.; Safiri, S.; Asayesh, H and Motlagh, M.E. (2017). Physical inactivity and associated factors in Iranian children and adolescents: the weight disorders survey of the CASPIAN-IV study. Journal of Cardiovascular and Thoracic Research. 9(1): 41-48.

Kelly, A. S.; Steinberger, J.; Olson, T. P and Dengel, D. R. (2007). In the absence of weight loss, exercise training does not improve adipokines or oxidative stress in overweight children. Metabolism. 56(7): 1005-1009.

Kim, H.; Baek, S.; Hong, S.M.; Lee, J.; Jung, S.M.; Lee, J.; Cho, M.L.; Kwok, S.K. and Park, S.H. (2020 a). 1, 25-dihydroxy vitamin D3 and interleukin-6 blockade synergistically regulate rheumatoid arthritis by suppressing interleukin 17 production and osteoclastogenesis. Journal of Korean Medical Science. 35(6): 40-50.

Kurutas, E. B. (2015). The importance of antioxidants which play the role in cellular response against oxidative/nitrosative stress: current state. Nutrition Journal. 15(1): 1-22.

Liang, L.; Su, W.; Zhou, L.; Cao, Y.; Zhou, X.; Liu, S.; Zhao, Y.; Ding, X.; Wang, Q and Zhang, H. (2020). Statin downregulation of miR-652-3p protects endothelium from dyslipidemia by promoting ISL1 expression. Metabolism. 107: 1-11.

López, I. P.; Marti, A.; Milagro, F. I.; Zulet, M. D. L. A.; Moreno-Aliaga, M. J.; Martinez, J. A and De Miguel, C. (2003). DNA microarray analysis of genes differentially expressed in diet-induced (cafeteria) obese rats. Obesity research. 11(2): 188-194.

Mahmoudi, A.; Samani, K. G.; Amini, S. A and Heidarian, E. (2019). Effects of pioglitazone on the lipid profile, serum antioxidant capacity, and UCP1 gene expression in mouse brown adipose tissue. Reports of Biochemistry and Molecular Biology. 8(1): 15-20.

McCord, J. M. (1987). Oxygen-derived radicals: a link between reperfusion injury and inflammation. Federation Proceedings. 46(7): 2402-2406.

Mostafa, D.K.; Nasra, R.A.; Zahran, N. and Ghoneim, M.T. (2016). Pleiotropic protective effects of vitamin D against high-fat diet-induced metabolic syndrome in rats: One for all. European Journal of Pharmacology. 792: 38-47.

Moukayed, M and Grant, W.B. (2019). Linking the metabolic syndrome and obesity with vitamin D status: risks and opportunities for improving cardiometabolic health and well-being. Diabetes, Metabolic Syndrome and Obesity: Targets and Therapy. 12: 1437-1447.

Nazima, B.; Manoharan, V and Prabu, S. M. (2014). Protective role of grape seed proanthocyanidins against cadmium-induced hepatic dysfunction in rats. Toxicology Research. 3(2):131-141.

Ni, Y. Ni, L. Zhuge, F. Xu, L. Fu, Z \& Ota, T. (2020). Adipose tissue macrophage phenotypes and characteristics: the key to insulin resistance in obesity and metabolic disorders. Obesity. 28(2): 225-234.

Nicholls, S. J.; Tuzcu, E. M.; Sipahi, I.; Schoenhagen, P.; Hazen, S. L.; Ntanios, F.; Ntanios, F.; Wun, C.C and Nissen, S.E. (2006). Effects of obesity on lipid-lowering, antiinflammatory, and anti-atherosclerotic benefits of Atorvastatin or Pravastatin in patients

48

Copyright (C 2020-2021, Journal of Scientific Research in Medical and Biological Sciences (JSRMBS), Under the license CC BY- 4.0 
with coronary artery disease (from the REVERSAL Study). The American Journal of Cardiology. 97(11): 1553-1557.

Noeman, S. A.; Hamooda, H. E and Baalash, A. A. (2011). Biochemical study of oxidative stress markers in the liver, kidney and heart of high-fat diet induced obesity in rats. Diabetology and Metabolic Syndrome. 3(1): 1-8.

Ohkawa, H.; Ohishi, N and Yagi, K. (1979). Assay for lipid peroxides in animal tissues by thiobarbituric acid reaction. Analytical Biochemistry. 95(2): 351358.

Pan, H.; Yang, Q.; Huang, G.; Ding, C.; Cao, P.; Huang, L.; Xiao, T.; Guo, J and Su, Z. (2016). Hypolipidemic effects of chitosan and its derivatives in hyperlipidemic rats induced by a high-fat diet. Food and Nutrition Research. 60(1): 1-13.

Polidoro, L.; Properzi, G.; Marampon, F.; Gravina, G.L.; Festuccia, C.; Di Cesare, E.; Scarsella, L.; Ciccarelli, C.; Zani, B.M. and Ferri, C.L.A.U.D.I.O. (2013). Vitamin D protects human endothelial cells from $\mathrm{H}_{2} \mathrm{O}_{2}$ oxidant injury through the Mek/Erk-Sirt1 axis activation. Journal of Cardiovascular Translational Research. 6(2): 221-231.

Popkin, B. M and Hawkes, C. (2016). Sweetening of the global diet, particularly beverages: patterns, trends, and policy responses. The Lancet Diabetes and Endocrinology. 4(2): 174-186.

Reid, M. B and Li, Y. P. (2001). Cytokines and oxidative signalling in skeletal muscle. Acta physiologica scandinavica. 171(3): 225-232.

Repetto, M.; Semprine, J and Boveris, A. (2012). Lipid peroxidation: chemical mechanism, biological implications and analytical determination. Lipid Peroxidation. 1: 3-30.

Rodrigues, G.; Moreira, A.J.; Bona, S.; Schemitt, E.; Marroni, C.A.; Di Naso, F.C.; Dias, A.S.; Pires, T.R.; Picada, J.N and Marroni, N.P. (2019). Simvastatin reduces hepatic oxidative stress and endoplasmic reticulum stress in nonalcoholic steatohepatitis experimental model. Oxidative Medicine and Cellular Longevity. 2019: 1-11.

Sahid, M. N. A.; Liu, S.; Kiyoi, T and Maeyama, K. (2017). Inhibition of the mevalonate pathway by Simvastatin interferes with mast cell degranulation by disrupting the interaction between Rab27a and double C2 alpha proteins. European Journal of Pharmacology. 814: 255-263.

Sobesky, J. L.; Barrientos, R. M.; Henning, S.; Thompson, B. M.; Weber, M. D.; Watkins, L. R and Maier, S. F. (2014). High-fat diet consumption disrupts memory and primes elevations in hippocampal IL-1 $\beta$, an effect that can be prevented with dietary reversal or IL-1 receptor antagonism. Brain, Behavior, and Immunity. 42: 22-32.

Uciechowski, P and Dempke, W. C. (2020). Interleukin-6: a Masterplayer in the cytokine network. Oncology. 98(3): 131-137.

Vallgårda, S.; Nielsen, M.E.J.; Hansen, A.K.K.; Cathaoir, K.Ó.; Hartlev, M.; Holm, L.; Christensen, B.J.; Jensen, J.D.; Sørensen, T.I and Sandøe, P. (2017). Should Europe follow the US and declare obesity a disease?: a discussion of the so-called utilitarian argument. European Journal of Clinical Nutrition. 71(11): 1263-1267. 
van Ginkel, G and Sevanian, A. (1994). Lipid peroxidation-induced membrane structural alterations. Methods in Enzymology. 233: 273-288.

Von Diemen, V.; Trindade, E. N and Trindade, M. R. M. (2006). Experimental model to induce obesity in rats. Acta Cirurgica Brasileira. 21(6): 425-429.

Wang, N.; Liang, H and Zen, K. (2014). Molecular mechanisms that influence the macrophage M1-M2 polarization balance. Frontiers in Immunology. 5: 1-9.

Warolin, J.; Coenen, K.R.; Kantor, J.L.; Whitaker, L.E.; Wang, L.; Acra, S.A.; Roberts, L.J and Buchowski, M.S. (2014). The relationship of oxidative stress, adiposity and metabolic risk factors in healthy Black and White American youth. Pediatric Obesity. 9(1): 43-52.

Wu, C.C.; Chang, J.H.; Chen, C.C.; Su, S.B.; Yang, L.K.; Ma, W.Y.; Zheng, C.M.; Diang, L.K and Lu, K.C. (2011). Calcitriol treatment attenuates inflammation and oxidative stress in hemodialysis patients with secondary hyperparathyroidism. The Tohoku Journal of Experimental Medicine. 223(3): 153159. 